\title{
Optimization of pretreatment of Jatropha oil with high free fatty acids for biodiesel production
}

\author{
Supriyono SUWITO ${ }^{1,2}$, Giuliano DRAGONE (凶) ${ }^{1}$, Hary SULISTYO ${ }^{2}$, Bardi MURACHMAN ${ }^{2}$, \\ Suryo PURWONO ${ }^{2}$, José TEIXEIRA ${ }^{1}$ \\ 1 Institute for Biotechnology and Bioengineering, Centre of Biological Engineering, University of Minho, Braga 4710-057, Portugal \\ 2 Chemical Engineering Department, Gadjah Mada University, Yogyakarta 55281, Indonesia
}

(C) Higher Education Press and Springer-Verlag Berlin Heidelberg 2012

\begin{abstract}
A central composite rotatable design and response surface methodology were used in order to investigate the individual and combined effects of the ethanol-to-oil ratio, $\mathrm{H}_{2} \mathrm{SO}_{4}$ concentration, temperature and time of reaction on the reduction of free fatty acid (FFA) in jatropha oil. A quadratic polynomial model relating the reaction variables with FFA reduction was developed, presenting a good coefficient of determination $\left(R^{2}=0.893\right)$. For reducing FFA to less than $1 \%$, the optimal combination was found to be $0.62 \mathrm{v} \cdot \mathrm{v}^{-1}$ ethanol-to-oil ratio $\left(14.9 \mathrm{v} \cdot \mathrm{v}^{-1}\right.$ ethanol-to-FFA ratio), $1.7 \% \mathrm{v} \cdot \mathrm{v}^{-1} \mathrm{H}_{2} \mathrm{SO}_{4}$ concentration, and 79 min reaction time at a reaction temperature of $54^{\circ} \mathrm{C}$. These results are of great relevance to maximize methyl esters formation by transesterification using an alkaline catalyst.
\end{abstract}

Keywords biodiesel, biofuel, esterification, free fatty acids, jatropha curcas oil

\section{Introduction}

Biodiesel produced from renewable feedstocks is receiving an increased interest worldwide as an alternative diesel fuel [1]. This biodegradable and non-toxic biofuel is composed of simple alkyl esters of fatty acids obtained by transesterification of triglycerides with low-molecular weight alcohols, such as methanol and ethanol [2]. Biodiesel can be used unmixed or blended at various percentages with conventional fossil diesel fuel in diesel engines or as a heating fuel [3].

Notwithstanding these attributes, the high cost of the most commonly-used feedstocks (partially or fully refined and edible-grade vegetable oils) affects the cost of

Received November 20, 2011; accepted March 2, 2012

E-mail: gdragone@deb.uminho.pt biodiesel production up to $60 \%-75 \%$, being the major bottleneck that greatly limits its widespread commercialization [4]. Therefore, using less expensive feedstocks such as non-edible oils, animal fats, waste cooking oils and byproducts of vegetables oil refinery can be regarded as an effective way of reducing production costs, particularly in developing countries [5].

In this sense, Jatropha curcas L. oil can be considered as a potential cheap feedstock for biodiesel production in comparison with refined and edible oils such as those obtained from rapeseed, soybean and sunflower that are commonly used in Europe and USA [2]. However, jatropha oil is prone to gradual deterioration due to unsuitable handling and improper storage conditions. Furthermore, increasing free fatty acid (FFA) concentration has been found in this oil when exposed to atmospheric air and sunlight for long time $[5,6]$. It has been reported that jatropha oil may contain up to $14 \%$ FFA, which is well above the limit of $1 \%$ FFA required for a satisfactory conversion into biodiesel by base catalyzed transesterification [7].

High levels of FFA have significant effects on the transesterification of triglycerides as FFA reacts with the alkali catalyst to form soaps, resulting in serious emulsification and separation problems. Thus, the additional washing step required to remove the soap from the biodiesel to maintain its quality leads to lower yields of product formation [8]. Hence, a suitable procedure must be developed in order to reduce the content of FFA [9].

Some studies have shown that high yields of biodiesel can be attained by using a two stage process, i.e., an initial pretreatment (esterification) with acid catalyst followed by transesterification with base catalyst [10]. Esterification catalyzed by homogeneous acids, such as sulfuric, phosphorous, and sulfonic acids, is a conventional and useful procedure to reduce the content of FFA, which can turn the oils transesterificable by an alkali catalyst [11]. 
Therefore, the objective of this work was to optimize the conditions of esterification for reducing the FFA content of jatropha oil. Assays were carried out according to central composite rotatable design (CCRD) and response surface methodology (RSM) in order to understand the interaction of the factors affecting FFA reduction.

\section{Materials and method}

\subsection{Materials}

Refined jatropha oil was supplied by ATMI (Akademi Teknik Mesin Indonesia), Surakarta, Indonesia. Some physical and chemical properties of this oil are shown in Table 1. Jatropha oil presented a greenish yellow color and had an initial acid value of $8.3 \pm 0.3 \mathrm{mg} \mathrm{KOH} / \mathrm{g}$ corresponding to a FFA level of $4.15 \pm 0.15 \%$, which is higher than the $1 \%$ limit for satisfactory transesterification reaction using alkaline catalyst [7].

Table 1 Fatty acid composition and physical properties of jatropha oil used in this study

\begin{tabular}{lc}
\hline Fatty Acid $/ \%$ & 0.04 \\
Caprylic & 0.06 \\
Capric & 0.02 \\
Lauric & 0.09 \\
Myristic & 0.82 \\
Palmitoleic & 14.09 \\
Palmitic & 0.23 \\
Margaric & 75.82 \\
Oleic & 7.93 \\
Stearic & 0.09 \\
Linoleic & 0.04 \\
Linolenic & 0.15 \\
Eicosenoic & 0.33 \\
Eicosanoic & 0.09 \\
Eicosenoic & 0.08 \\
Eicosapentaenoic & 0.03 \\
Behenic & 0.01 \\
Docosatrienoic & 0.04 \\
Decahexanoic & $<0.001$ \\
Teracosanoic & 42.765 \\
Kinematic viscosity $/\left(40^{\circ} \mathrm{C}, \mathrm{mm}^{2} \cdot \mathrm{s}^{-1}\right)$ & 0.2 \\
Water content $/($ vol- $\%)$ & 0.9184 \\
Specific gravity at $60 / 60^{\circ} \mathrm{C}$ & 374 \\
Flash point PMcc $/{ }^{\circ} \mathrm{F}$ & 1.052 \\
Conradson carbon $\mathrm{residue} /(\mathrm{wt}-\%)$ & 182 \\
Saponification value $/\left(\mathrm{mg} \cdot \mathrm{g}^{-1}\right)$ & 0.61 \\
Peroxide value & \\
\hline
\end{tabular}

Table 2 Levels and range of the independent variables used in the esterification process according to CCRD

\begin{tabular}{lcccc}
\hline Independent variable & Symbol & -1 & Levels and range \\
\cline { 3 - 5 } & & EtO & 0.3 & 0 \\
\hline Ethanol-to-oil ratio $/\left({\left.\mathrm{v} \cdot \mathrm{v}^{-1}\right)}^{2}\right.$ & $\mathrm{Ac}$ & 1 & 0.5 & 0.7 \\
$\mathrm{H}_{2} \mathrm{SO}_{4}$ concentration $/(\mathrm{vol}-\%)$ & $\mathrm{Ti}$ & 50 & 2 & 3 \\
Time $/$ min & $\mathrm{Te}$ & 45 & 70 & 90 \\
Temperature $/{ }^{\circ} \mathrm{C}$ & & & 55 & 65 \\
\hline
\end{tabular}

All chemicals used in the experiments were of analytical reagent (AR) grade. Ethanol (99.5\%), sulfuric acid (96\% 98\%) and potassium hydroxide were purchased from Panreac, Spain. Potassium hydrogen phthalate was purchased from Riedel de Haen, Germany.

\subsection{Equipment}

Esterification of FFA in jatropha oil was performed in $125 \mathrm{~mL}$ rounded glass flasks equipped with a spiral condenser. A magnetic stirrer was used to homogenize the solution and a controlled water bath was employed to maintain a constant temperature throughout the experiment.

\subsection{Esterification}

Jatropha oil was poured into the rounded flask and heated up to the desired temperature. Then, ethanol and sulfuric acid were mixed with the oil and time was started to count. At the end of the experiment, the reacting mixture was transferred into a separation funnel. The oil phase was separated and centrifuged at $5000 \mathrm{rpm}$ during $5 \mathrm{~min}$. The FFA content of the oil phase was then determined by standard titration using potassium hydroxide $(\mathrm{KOH})$ [12].

2.4 Experimental design and optimization by response surface methodology

A three-level-four-factor CCRD leading to 29 sets of experiments was employed in this study to establish the influence of the variables: ethanol-to-oil ratio (EtO), acid catalyst concentration (Ac), temperature (Te) and time of reaction (Ti) on the FFA reduction of jatropha oil. For statistical analysis, the independent variables were coded according to Eq. (1), where each independent variable is represented by $x_{i}$ (coded value), $X_{i}$ (real value), $X_{0}$ (real value at the center point) and $\Delta X_{i}$ (step change value). The coding facilitated the computation for regression analysis.

$$
x_{i}=\left(X_{i}-X_{0}\right) / \Delta X_{i} .
$$

The range and levels of the variables are given in Table 2.

The experiment in the central point was replicated five times to provide sufficient degrees of freedom for estimating the purely experimental uncertainty variance. 
The experimental results were fitted with a second-order polynomial equation by multiple regression analysis. The quadratic model for predicting the optimal point was expressed according to Eq. (2), where $\hat{y}_{i}$ represents the response variable, $b_{0}$ is the interception coefficient, $b_{i}, b_{i i}$ and $b_{i j}$ are the regression coefficients, $\mathrm{n}$ is the number of studied variables, and $X_{i}$ and $X_{j}$ represent the independent variables. Where possible, the model was simplified by elimination of statistically insignificant terms.

$$
\hat{y}_{i}=b_{0}+\sum_{i=1}^{n} b_{i} X_{i}+\sum_{i=1}^{n} b_{i i} X_{i}^{2}+\sum_{i=1}^{n-1} \sum_{j=i+1}^{n} b_{i j} X_{i} X_{j} .
$$

The quality of the fitted polynomial model was expressed by the coefficient of determination $R^{2}$, and its statistical significance was checked by the $F$-test. The significance of the regression coefficients was tested by $t$ value. Results were analyzed by the Experimental Design Module of the Statistica 8.0 software (Statsoft, USA). The model permitted evaluation of the effects of linear, quadratic and interactive terms of the independent variables on the chosen dependent variables.

\section{Results and discussion}

Previous studies have reported that alkaline transesterification of jatropha oil containing more than 1\% FFA presents significant drawbacks due to the formation of fatty acid salts (soap). The soaps promote the formation of stable emulsions that prevent separation of the methyl ester layer from the glycerin during processing and also reduce the

Table 3 Observed and predicted values of the reduction of FFA content in jatropha oil according to the full-factorial CCRD

\begin{tabular}{|c|c|c|c|c|c|c|}
\hline \multirow{2}{*}{ Run } & \multirow{2}{*}{$\mathrm{H}_{2} \mathrm{SO}_{4} /($ vol- $\%)$} & \multirow{2}{*}{ Ethanol: oil $/\left(\mathrm{v} \cdot \mathrm{v}^{-1}\right)$} & \multirow{2}{*}{ Time $/ \mathrm{min}$} & \multirow{2}{*}{ Temperature $/{ }^{\circ} \mathrm{C}$} & \multicolumn{2}{|c|}{ FFA reduction } \\
\hline & & & & & Experimental & Predicted \\
\hline 17 & 1 & 0.5 & 70 & 55 & 3.80 & 3.14 \\
\hline 1 & 1 & 0.3 & 50 & 45 & 2.56 & 2.29 \\
\hline 2 & 1 & 0.3 & 50 & 65 & 3.09 & 2.67 \\
\hline 3 & 1 & 0.3 & 90 & 45 & 2.93 & 2.58 \\
\hline 4 & 1 & 0.3 & 90 & 65 & 2.98 & 2.16 \\
\hline 5 & 1 & 0.7 & 50 & 45 & 3.35 & 3.13 \\
\hline 6 & 1 & 0.7 & 50 & 65 & 3.59 & 3.45 \\
\hline 7 & 1 & 0.7 & 90 & 45 & 3.55 & 3.05 \\
\hline 8 & 1 & 0.7 & 90 & 65 & 3.37 & 2.57 \\
\hline 19 & 2 & 0.3 & 70 & 55 & 3.03 & 2.71 \\
\hline 21 & 2 & 0.5 & 50 & 55 & 3.66 & 3.26 \\
\hline 23 & 2 & 0.5 & 70 & 45 & 3.54 & 3.08 \\
\hline $29(\mathrm{C})$ & 2 & 0.5 & 70 & 55 & 3.62 & 3.17 \\
\hline $25(\mathrm{C})$ & 2 & 0.5 & 70 & 55 & 3.60 & 3.17 \\
\hline $26(\mathrm{C})$ & 2 & 0.5 & 70 & 55 & 3.64 & 3.17 \\
\hline $28(\mathrm{C})$ & 2 & 0.5 & 70 & 55 & 3.66 & 3.17 \\
\hline $27(\mathrm{C})$ & 2 & 0.5 & 70 & 55 & 3.64 & 3.17 \\
\hline 24 & 2 & 0.5 & 70 & 65 & 3.31 & 2.87 \\
\hline 22 & 2 & 0.5 & 90 & 55 & 3.58 & 3.08 \\
\hline 20 & 2 & 0.7 & 70 & 55 & 3.85 & 3.23 \\
\hline 9 & 3 & 0.3 & 50 & 45 & 2.60 & 2.49 \\
\hline 10 & 3 & 0.3 & 50 & 65 & 2.89 & 2.55 \\
\hline 11 & 3 & 0.3 & 90 & 45 & 3.69 & 3.01 \\
\hline 12 & 3 & 0.3 & 90 & 65 & 2.93 & 2.27 \\
\hline 18 & 3 & 0.5 & 70 & 55 & 3.43 & 3.18 \\
\hline 13 & 3 & 0.7 & 50 & 45 & 3.38 & 3.11 \\
\hline 14 & 3 & 0.7 & 50 & 65 & 3.42 & 3.11 \\
\hline 15 & 3 & 0.7 & 90 & 45 & 3.48 & 3.27 \\
\hline 16 & 3 & 0.7 & 90 & 65 & 3.25 & 2.47 \\
\hline
\end{tabular}


ester conversion rate [5]. On the other hand, an acidcatalyzed esterification of the FFA followed by basecatalyzed transesterification appears to be an effective and efficient method to obtain biodiesel from high FFA feedstocks [13].

Esterification of FFA with an alcohol is a reversible reaction, which is catalyzed by acids to produce fatty acid alkyl esters and water [12], as shown below:

$$
\mathrm{R}_{1}-\mathrm{COOH}+\mathrm{R}_{2}-\mathrm{OH} \leftrightarrow \mathrm{R}_{1}-\mathrm{COO}-\mathrm{R}_{2}+\mathrm{H}_{2} \mathrm{O}
$$

The rate and conversion efficiency of acid esterification can be affected by several factors, among which, alcohol type, alcohol-to-oil ratio, acid catalyst concentration, reaction temperature, and reaction time have been regarded as the most important $[2,5]$. Thus, a number of studies on the esterification [11,14-16] have been performed by changing one of these factors separately at a time (COST). However, reaction system influenced simultaneously by more than one factor can be poorly understood with the COST-approach [17].

Therefore, our study evaluated the simultaneous effect of ethanol-to-oil ratio, $\mathrm{H}_{2} \mathrm{SO}_{4}$ concentration, temperature and time of reaction on the reduction of FFA of jatropha oil by using CCRD. According to Canacki et al. [13], a higher rate of esterification can be obtained by using ethanol rather than methanol due to its higher solubility in oils and fats. In addition, Marchetti and Errazu [15] employed ethanol instead of methanol for the esterification of FFA with sulfuric acid, since ethanol is less toxic and safer to handle.

\subsection{Statistical analysis of FFA reduction}

The experimental results obtained for the reduction of FFA of jatropha oil under different operational conditions according to the $2^{4}$ CCRD are shown in Table 3. It can be noted that FFA decreased under all the evaluated conditions, however, the reduction strongly varied according to the levels employed for the independent variables.

Due to the large difference observed in the FFA reduction, a statistical analysis was carried out to identify the variables that had the greatest influence on this process. Table 4 shows the Student's $t$-test and $p$-values used to determine the statistical significance of the independent variables (ethanol-to-oil ratio, $\mathrm{H}_{2} \mathrm{SO}_{4}$ concentration, temperature and time of reaction) on the response variable (reduction of FFA). According to this analysis the ethanolto-oil ratio was the only variable with significant (at $95 \%$ confidence level) individual effect on FFA reduction. Such effect had a positive signal, indicating that FFA reduction increased by increasing the initial ratio between ethanol and oil. Interaction effects between ethanol-to-oil ratio and time and between time and temperature were also significant at $95 \%$ confidence level.

After identification of the variable affecting the reduction of FFA of jatropha oil, a multiple regression analysis was performed to fit the experimental data to a polynomial equation, obtaining the coefficients given below.

$$
\begin{gathered}
\text { FFA reduction }(\%)=-9.550+0.438 \mathrm{Ac}-0.012 \mathrm{Ac}^{2} \\
+8.803 \mathrm{EtO}-4.974 \mathrm{EtO}^{2}+0.056 \mathrm{Ti}+0.299 \mathrm{Te} \\
-0.002 \mathrm{Te}^{2}-0.272 \mathrm{AcEtO}+0.003 \mathrm{AcTi}-0.008 \mathrm{AcTe} \\
-0.023 \mathrm{EtOTi}-0.007 \mathrm{EtOTe}-0.001 \mathrm{TiTe}
\end{gathered}
$$

where $\mathrm{Ac}=$ acid catalyst concentration $\left(\%, \mathrm{v} \cdot \mathrm{v}^{-1}\right), \mathrm{EtO}=$ ethanol-to-oil ratio $\left(\mathrm{v} \cdot \mathrm{v}^{-1}\right), \mathrm{Ti}=$ time of reaction $(\mathrm{min})$ and

\begin{tabular}{|c|c|c|c|c|}
\hline Variables and interactions $^{\text {a) }}$ & Estimated effects & Standard errors & $t$-value & $p$-value \\
\hline Ac $(L)$ & -0.019 & 0.075 & -0.248 & 0.808 \\
\hline Ac $(Q)$ & -0.024 & 0.192 & -0.124 & 0.903 \\
\hline EtO (L) & 0.504 & 0.076 & 6.676 & 0.000 \\
\hline EtO (Q) & -0.398 & 0.198 & -2.005 & 0.065 \\
\hline $\mathrm{Ti}(\mathrm{L})$ & 0.136 & 0.076 & 1.806 & 0.092 \\
\hline $\mathrm{Ti}(\mathrm{Q})$ & -0.042 & 0.198 & -0.210 & 0.836 \\
\hline $\mathrm{Te}(\mathrm{L})$ & -0.027 & 0.076 & -0.356 & 0.727 \\
\hline $\mathrm{Te}(\mathrm{Q})$ & -0.421 & 0.198 & -2.121 & 0.052 \\
\hline Ac EtO & -0.109 & 0.080 & -1.357 & 0.196 \\
\hline Ac $\mathrm{Ti}$ & 0.102 & 0.080 & 1.270 & 0.225 \\
\hline $\mathrm{Ac} \mathrm{Te}$ & -0.161 & 0.080 & -2.005 & 0.065 \\
\hline EtO Ti & -0.186 & 0.080 & -2.327 & 0.035 \\
\hline EtO Te & -0.029 & 0.080 & -0.359 & 0.725 \\
\hline $\mathrm{Ti} \mathrm{Te}$ & -0.279 & 0.080 & -3.482 & 0.004 \\
\hline
\end{tabular}
$\mathrm{Te}=$ temperature $\left({ }^{\circ} \mathrm{C}\right)$. The quality of the fitted polynomial model was expressed by the coefficient of determination $\left(R^{2}\right)$. Variables with no significant effects at $p<0.05$ were

Table 4 Effect estimates, standard errors, $t$-test and $p$-values for the reduction of FFA content in jatropha oil according to the full-factorial CCRD

a) (L): linear; (Q): quadratic 
maintained in the model to not decrease the value of $R^{2}$. As can be noted, the model explains nearly $90 \%$ of the variability observed in the response $\left(R^{2}=0.893\right)$. The high $R^{2}$ value means that the model accurately represents the data in the experimental region studied. The values predicted by the model are displayed in Table 3 along with the observed values. Comparison of these values indicates that there is a good agreement between the model and experimental data for the range of experimental values tested.

The relation between independent variables and FFA reduction can be best visualized by examining the contour plots presented in Fig. 1.

Figure 1(a) clearly shows that increasing the ethanol-tooil ratio resulted in higher FFA reduction for an acid catalyst concentration between $1 \%$ and $3 \%$, with maxima values of reduction $(\geqslant 3.6 \%)$ being achieved when the ratio was higher than 0.5 (ethanol-to-FFA ratio $>12.0$ ). It can also be observed in Fig. 1(b) that ethanol-to-oil ratios higher than 0.5 lead to the highest reduction of FFA of jatropha oil when the time of reaction was between 50 and $90 \mathrm{~min}$. These results are in agreement with those reported by Azhari et al. [14]. According to these authors, FFA concentration decreases sharply after $60 \mathrm{~min}$ of reaction by using an alcohol (methanol)-to-oil ratio higher than 0.5 . Deng et al. [2] also demonstrated that FFA of jatropha oil can be reduced from $3.21 \%$ to $0.605 \%$ as methanol-to-oil ratio is increased from 0.16 to 0.40 (5.0 to 12.5 methanolto-FFA ratio).

The reduction of FFA of jatropha oil increased as the temperature was raised from $45^{\circ} \mathrm{C}$ up to $60^{\circ} \mathrm{C}$ using $\mathrm{H}_{2} \mathrm{SO}_{4}$ concentrations between 1 and 3\% (Fig. 1(c)). This result confirms the earlier findings of Marchetti and Errazu [15] where the final FFA conversion increased as temperature increased from $35^{\circ} \mathrm{C}$ to $55^{\circ} \mathrm{C}$. According to these authors, the reaction was typically endothermic. On the other hand, the lower FFA reductions observed at temperatures higher than $60^{\circ} \mathrm{C}$ can be related to a higher evaporation of ethanol.

The statistical model (Eq. (3)) predicted that the highest reduction of FFA can be obtained for the following optimized reaction conditions: an ethanol-to-oil ratio of 0.62 (ethanol-to-FFA ratio of 14.9), an acid catalyst concentration of $1.7 \%$, temperature of $54^{\circ} \mathrm{C}$ and a reaction time of $79 \mathrm{~min}$. Thus, additional experiments were carried out to validate the equation using these optimal values. The experimental value of FFA reduction (3.45\%) obtained by using the optimized conditions agreed well with the predicted value $(3.20 \%)$, and thus confirmed the adequacy of the predicted model.

\section{Conclusions}

The high FFA level of jatropha oil was reduced to less than $1 \%$ by its pretreatment with ethanol-to-oil ratio of 0.62 (ethanol-to-FFA ratio of 14.9) using $\mathrm{H}_{2} \mathrm{SO}_{4}\left(1.7 \%\right.$ ) at $54^{\circ} \mathrm{C}$
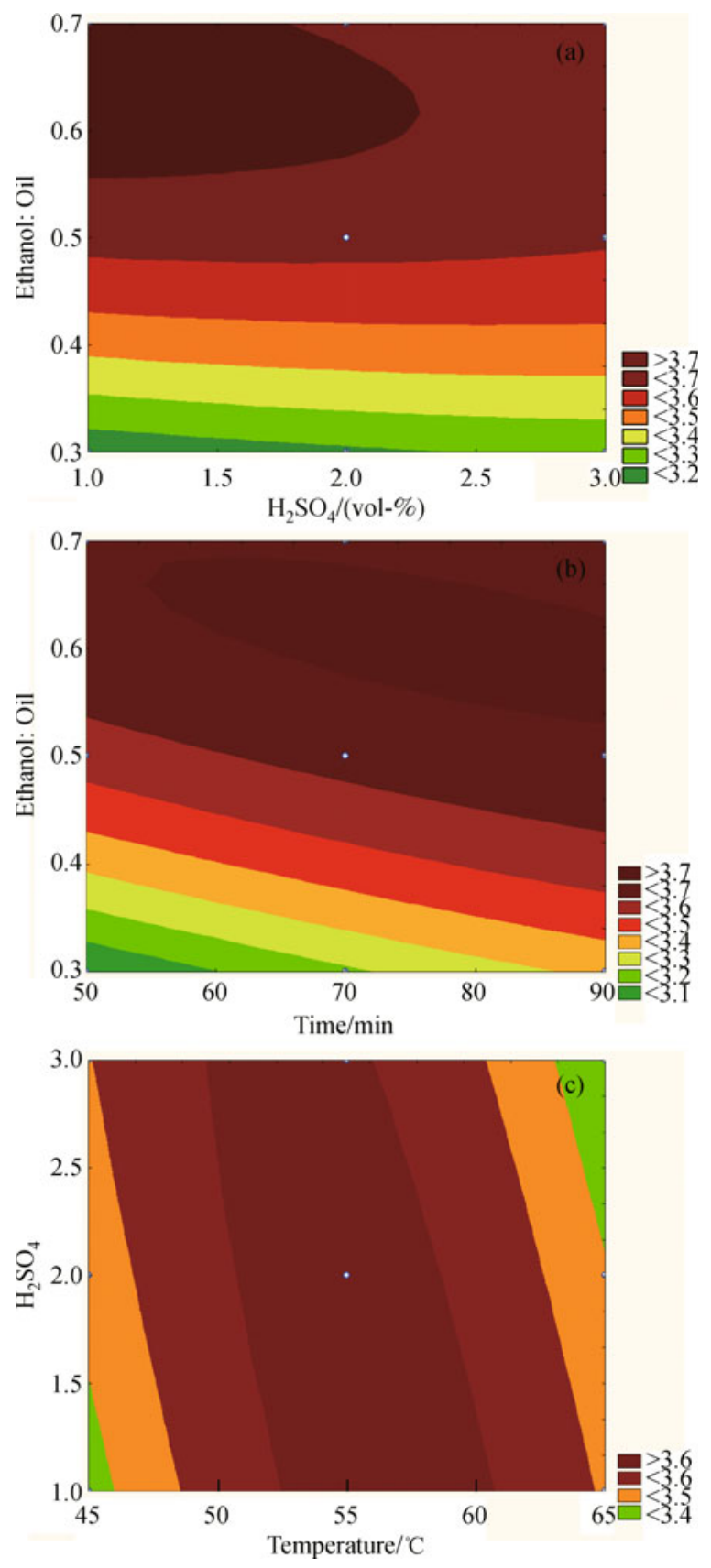

Fig. 1 Contour plots of FFA reduction (\%) as a function of (a) ethanol-to-oil ratio and acid catalyst concentration, (b) ethanol-tooil ratio and time, and (c) acid catalyst concentration and temperature, predicted from the quadratic model.

during $79 \mathrm{~min}$. The quadratic polynomial model presented in this study was found to be highly significant with a coefficient of determination of 0.893 . These results are of great relevance to maximize methyl esters formation by transesterification using an alkaline catalyst.

Acknowledgements This work was supported by Fundação para a Ciência Technology through G. Dragone grant SFRH/BPD/44935/2008. The authors 
acknowledge financial support from project INNOVALGAE (PTDC/AAC$\mathrm{AMB} / 108511 / 2008)$.

\section{References}

1. Veljkovic V B, Lakicevic S H, Stamenkovic O S, Todorovic Z B, Lazic M L. Biodiesel production from tobacco (Nicotiana tabacum L.) seed oil with a high content of free fatty acids. Fuel, 2006, 85 (17-18): 2671-2675

2. Deng X, Fang Z, Liu Y. Liu Y H. Ultrasonic transesterification of Jatropha curcas L. oil to biodiesel by a two-step process. Energy Conversion and Management, 2010, 51(12): 2802-2807

3. Vicente G, Coteron A, Martinez M, Aracil J. Application of the factorial design of experiments and response surface methodology to optimize biodiesel production. Industrial Crops and Products, 1998, 8(1): 29-35

4. Çetinkaya M, Karaosmanoglu F. Optimization of base-catalyzed transesterification reaction of used cooking oil. Energy \& Fuels, 2004, 18(6): 1888-1895

5. Berchmans H J, Hirata S. Biodiesel production from crude Jatropha curcas L. seed oil with a high content of free fatty acids. Bioresource Technology, 2008, 99(6): 1716-1721

6. Syam A, Yunus R, Ghazi T, Yaw T. Methanolysis of jatropha oil in the presence of potassium hydroxide catalyst. Journal of Applied Sciences, 2009, 9(17): 3161-3165

7. Kumar Tiwari A, Kumar A, Raheman H. Biodiesel production from jatropha oil (Jatropha curcas) with high free fatty acids: an optimized process. Biomass and Bioenergy, 2007, 31(8): 569-575

8. Ghadge S V, Raheman H. Biodiesel production from mahua (Madhuca indica) oil having high free fatty acids. Biomass and
Bioenergy, 2005, 28(6): 601-605

9. Jena P C, Raheman H, Prasanna Kumar G V, Machavaram R. Biodiesel production from mixture of mahua and simarouba oils with high free fatty acids. Biomass and Bioenergy, 2010, 34(8): 1108-1116

10. Dorado M, Ballesteros E, de Almeida J, Schellert C, Lohrlein H, Krause R. An alkali-catalyzed transesterification process for high free fatty acid waste oils. Transactions-American Society Of Agricultural Engineers, 2002, 45(3): 525-530

11. Lu H, Liu Y, Zhou H, Yang Y, Chen M, Liang B. Production of biodiesel from Jatropha curcas L. oil. Computers \& Chemical Engineering, 2009, 33(5): 1091-1096

12. ASTM. American Standards for Testing of Materials. D 189-01 D, D 4052-96, D 445-03, D 482-74, D 5555-95, D 6751-02, D 9302, D 95-990, D 97-02. 2003

13. Canakci M, Gerpen J V. Biodiesel production from oils and fats with high free fatty acids. Transactions of the ASAE. American Society of Agricultural Engineers, 2001, 44(6): 1429-1436

14. Azhari M, Faiz M, Yunus R, Ghazi T, Yaw T. Reduction of free fatty acids in crude Jatropha curcas oil via an esterification process. International Journal of Engineering and Technology, 2008, 5(2): 92-98

15. Marchetti J M, Errazu A F. Esterification of free fatty acids using sulfuric acid as catalyst in the presence of triglycerides. Biomass and Bioenergy, 2008, 32(9): 892-895

16. Zhang J, Jiang L. Acid-catalyzed esterification of Zanthoxylum bungeanum seed oil with high free fatty acids for biodiesel production. Bioresource Technology, 2008, 99(18): 8995-8998

17. Yuan X, Liu J, Zeng G, Shi J, Tong J, Huang G. Optimization of conversion of waste rapeseed oil with high FFA to biodiesel using response surface methodology. Renewable Energy, 2008, 33(7): $1678-1684$ 